\title{
祁连山园柏年轮与我国近千年气候变化 和冰川进退的关系*
}

\author{
王玉堡 \\ 刘 光 远 \\ (兰州大学地质地理系)（中国科学院兰州冰川练土研究所） \\ 张先 恭 \\ 李 存 法 \\ （中央气象局天气气侯研究所,北京）(中国科学院兰州冰川陈土研究所）
}

冰川附近与高寒山地林带上限的单棵树木年轮能反映冰川进退和气候的变化 ${ }^{41-31}$. 因此， 我们将 1976-1978 年在祁连山林带上下限采集的四棵园 柏 (Sabina przewalskii Kom.) 的年 轮资料(其中最长的 935 年是我国目前所采集到的最长的年轮)作了全面分析, 研究了我国近

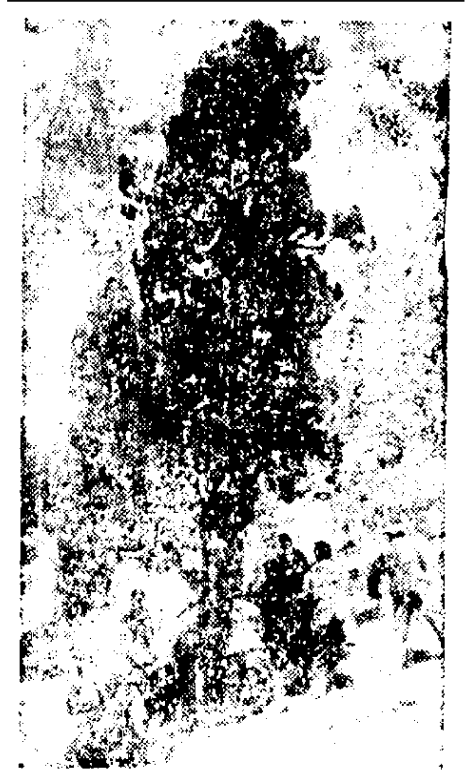

图 1 青海德令哈柏树山的 935 轮园柏. 王玉皿掫, 1978.8.22
千年来的气候变化 (见图 1、表 1).

对年轮序列作了生长量订正, 求出年轮指数 $I(t)^{[1]}$.

$$
I(t)=\frac{y(t)}{y^{\prime}(t)} / \frac{\sum_{t=1}^{N} \frac{y(t)}{y^{\prime}(t)}}{N}, \quad(t=1,2,3 \cdots, N) .
$$

表 1 园柏采伐时间和地点

\begin{tabular}{|c|c|c|c|c|c|}
\hline \multirow{2}{*}{$\begin{array}{l}\text { 样 本 } \\
\text { (轮数) }\end{array}$} & \multirow{2}{*}{$\begin{array}{c}\text { 拔海高度 } \\
\text { (米) }\end{array}$} & 宅 & 貫 & \multirow{2}{*}{$\begin{array}{l}\text { 采伐时间 } \\
\text { (年、月) }\end{array}$} & \multirow{2}{*}{ 坡 向 } \\
\hline & & 北纬 & 东经 & & \\
\hline 913 & 3670 & $37.0^{\circ}$ & $98.8^{\circ}$ & 1976.8 & 南坡 \\
\hline 935 & 3900 & $37.3^{\circ}$ & $97.2^{\circ}$ & 1978.8 & 南坡 \\
\hline 718 & 3750 & $37.3^{\circ}$ & $97.2^{\circ}$ & 1978.8 & 南坡 \\
\hline 296 & 2600 & $38.7^{\circ}$ & $99.9^{\circ}$ & 1976.8 & 北坡 \\
\hline
\end{tabular}

其中, $y(t)$ 是实际年轮宽, $y^{\prime}(t)$ 为年龄趋势, $t$ 为年轮序数, $N$ 为年轮总数.

敏感度是树木生长受气候因子影响程度 的大小. 平均敏感度 (MS) 公式:

$$
\text { MS }-\frac{1}{N-1} \sum_{i=1}^{N-1}\left|\frac{2\left(y(t)_{i+1}-y(t)_{i}\right)}{y(t)_{i+1}+y(t)_{i}}\right|,
$$

式中, $y(t)_{i}$ 为 $i$ 年的年轮宽度或指数, $N$ 为 年轮总数.

Fritts 在美国西部干旱地区的研究证明,

表 2 平均敏感度

\begin{tabular}{c|c|c}
\hline 位置 & 轮数 & MS \\
\hline 林带 & 718 & 0.289 \\
上限 & 913 & 0.290 \\
& 935 & 0.291 \\
\hline 下限 & 296 & 0.398 \\
\hline
\end{tabular}

本文 1980 年1月 2 日收到. 1982 年 4 月 23 日收到㤵改稿.

，参加影外采样工作的还有王初一;文中插国由兰州大学管玉芬清绘。 
一般树木 MS 在 $0-0.2$; 温度、水分条件限制严的地方，树木 MS 多在 0.3 以上 ${ }^{[4]}$.

MS 值计算结果在表 2. 可见,该四棵园柏反映气候变化的信息是相当好的.

由于 935、718、913 三棵园柏年轮宽度变化颇为一致(图 2), 故将三列资料平均, 平均指 数序列具有稳定而良好的代表性.

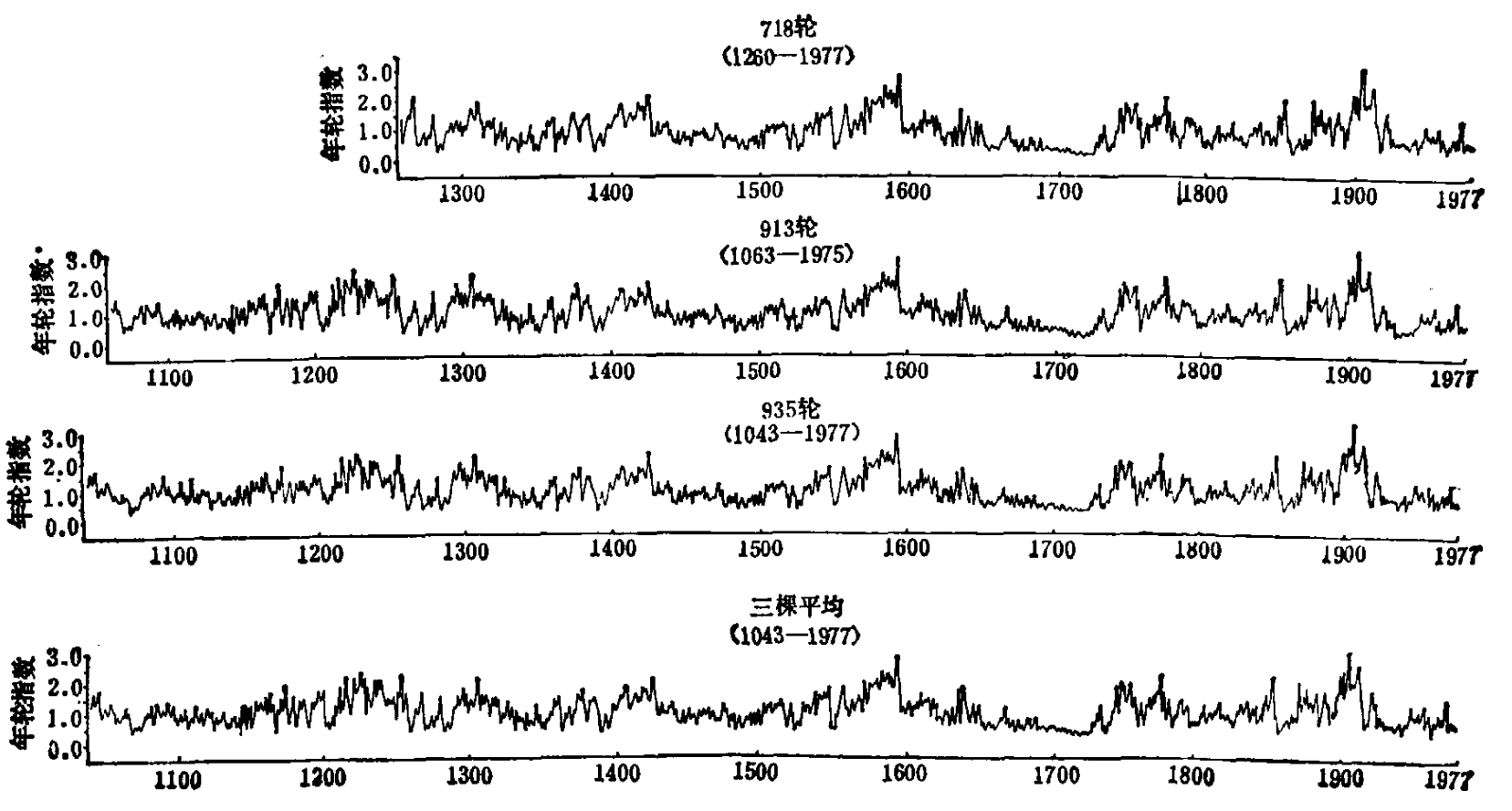

图 2 三棵年轮 $(718 、 913 、 935$ 轮) 指数及其平均指数曲线

\section{一、近千年来祁连山及我国气候的变化}

从 12 世纪 50 年代到 19 世纪 60 年代，存在着一个持续约六百多年的大周期. 其间冷暖 持续期各为七个 (图 3). 在图 4 中, 若以年轮平均指数的平均值 1.0 作为气候冷暖的界限, 则 祁连山九百多年来冷暖期各出现了七次和图 3 结果完全相符(见表 4).

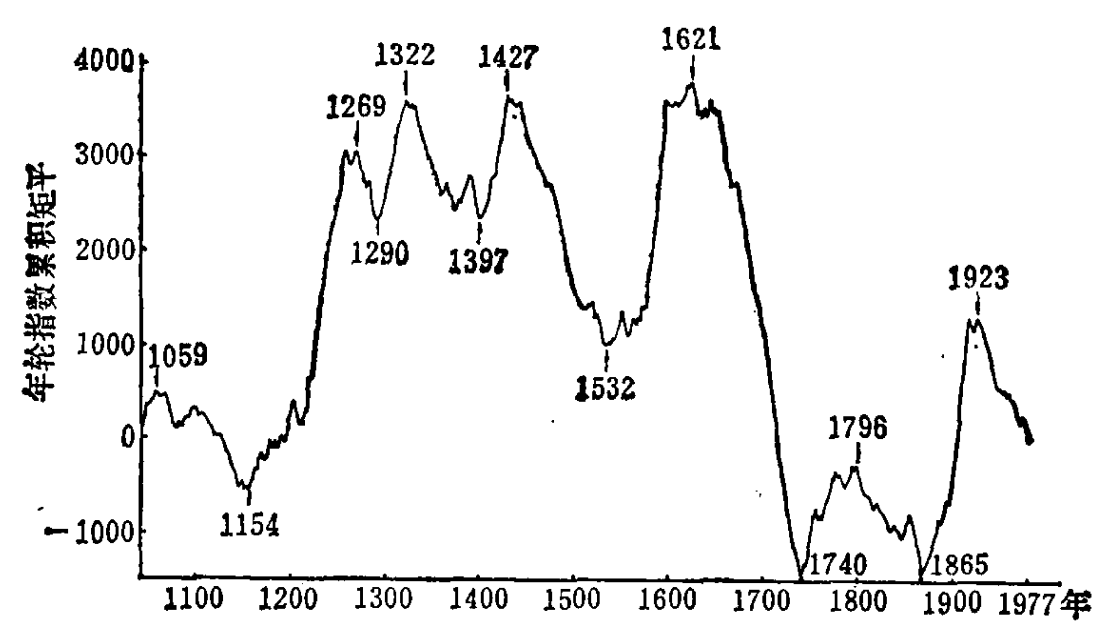

图 3 三棵年轮平均指数变化曲线 (1043-1977)

表 4 表明, 11 世纪至 12 世纪中为一个世纪左右的冷期, 但寒冷程度不深. 从 12 世纪 50 年代到 15 世纪 20 年代的 270 多年内基本上是一个温䁔期. 此后, 除了 16 世纪 30 年代初有 


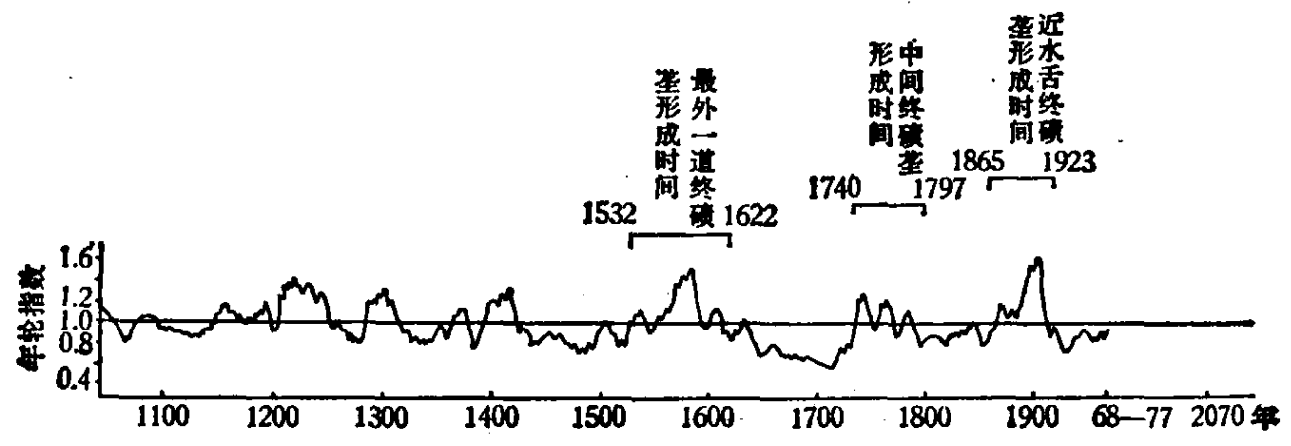

图 4 三堁年轮平均指数十年滑动平均值每十年变化曲线 (1043-1977)

表 4 初连山气候变化冷暖期的年份及持续期

\begin{tabular}{|c|c|c|c|c|c|}
\hline & & \multicolumn{2}{|c|}{ 暖 期 } & \multicolumn{2}{|l|}{ 冷 } \\
\hline & & 年份 & 持续期 & 年。妨 & 持续期 \\
\hline 1154 & $\begin{array}{l}1154 \\
\text { 冷期 }\end{array}$ & $(1043-1059)$ & (17) & $1060-1154$ & 95 \\
\hline \multirow{2}{*}{1865} & \multirow{2}{*}{$\begin{array}{c}1155 \\
1 \\
1427 \\
\text { 期 } \\
\text { (273 年) }\end{array}$} & $\begin{array}{l}1155-1269 \\
1291-1322 \\
1398-1427\end{array}$ & $\begin{array}{r}115 \\
32 \\
30\end{array}$ & $\begin{array}{l}1270-1290 \\
1323-1397\end{array}$ & $\begin{array}{l}21 \\
75\end{array}$ \\
\hline & & 总年数 & 177 & 总年数 & 96 \\
\hline \multirow[t]{2}{*}{ (711 年) } & $\begin{array}{c}1428 \\
1865 \\
\text { 冷期 }\end{array}$ & $\begin{array}{l}1533-1621 \\
1741-1796\end{array}$ & $\begin{array}{l}89 \\
56\end{array}$ & $\begin{array}{l}1428-1532 \\
1622-1740 \\
1797-1865\end{array}$ & $\begin{array}{r}105 \\
119 \\
69\end{array}$ \\
\hline & (437 年) & 总年数 & 145 & 总年数 & 293 \\
\hline \multirow[t]{2}{*}{$\frac{1866}{1}$} & $\left.\right|_{1866} ^{1866}$ & $1866-1923$ & 58 & $1924-(1977)$ & (54) \\
\hline & 平均 & & 57 & & 77 \\
\hline
\end{tabular}

一个 80 多年的暖期和 1741-1796 年的弱暧期外,一直到19世纪 60 年代末, 是一个寒冷最长的 时期. 其中 1428-1532、1622-1740、1797-1865 年为三个明显的寒冷期, 特别是 16221740 年的 119 年是最寒冷的时期. $1866-1923$ 年是一个很温暖的时期, 1924 年以来又进人 一个新的冷期. 其中平均持续期，冷期为 1977 年占 $58 \%$, 暖期为 1957 年占 $42 \%$, 可见近一 千年来气候以冷期为主.

䇥可桢曾研究了我国近五千年的气候变化 ${ }^{[5]}$. 从近一千年的气候变化来看，有两个明显 的寒冷期,一个在南宋 (12 世纪)，一个在明清(中心在 17 世纪). 1060-1154 年这一段冷期 就是南宋时代寒冷期的反映. 明清的寒冷期,对应于欧洲 16 世纪开始的所谓“现代小冰期”,其 主要寒期在公元 1725 年前后，这是我国近五千年来比较明显的一次气候振动。1428一1532、 $1622-1740 、 1797-1865$ 约 300 年的三个寒冷期, 可能就是以 1725 年为中心的明清寒冷期 的反映. 尤其是近 500 年来的两个暖期和三个冷期与筑可桢分析基本一致,其结果在文献 [6] 中也得到证实. 由分析可见，年轮的变化基本上反映了我国近千年来气候变化的主要趋势我 们用功率谱 ${ }^{[7]}$ 分析得出，我国祁连山气候变化具有 310-330、160-210、9-0130、60、26、 
$2-3$ 年的周期变化.

296 轮作谐波分析得出, 300 年来祁连山降水具有明显的 35 年左右的周期，与文献 [8]中 36 年旱港周期一致。

用方差分析预报未来 100 年内的气候变化，除 70 年代末至 80 年代初和下世纪 40 及 60 年代两次弱迴暖期外,其余均是寒冷的(图 5). 降水(图 5,296 轮曲线) 从现在起到下世纪 10 年代增加很大, 其中最近 80 年代降水接近 300 年来最高值.

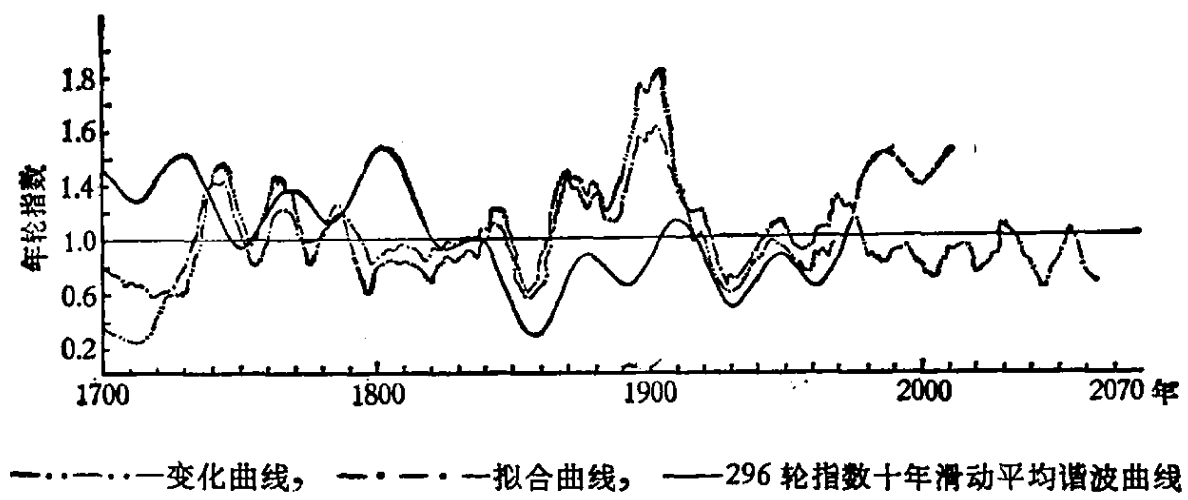

图 5 三棵年轮平均指数变化曲线及拟合、预报曲线 $(1700-1977)$

从本世纪 50 年代以来全世界气候有转冷的趋势 ${ }^{[0]}$, 在年轮变化上反映的很清梦, 只不过 是 1924 年开始,位相提前了 20 多年,这一点有待于进一步研究.

\section{二、冰川进退与年轮气候的关系}

冰川的进退和气候的冷暖变化有密切的关系. 从近几年的观测资料证明, 祁连山冰川雪 线高度已普遍下降, 冰川物质平衡已转为正值 ${ }^{[10]}$,少数冰川已出现前进,这就是本世纪 20 年代 以来寒冷阶段的反映,是冰川普遍性前进的预兆.

冰川的进退滞后于气候变化,小冰川10-20 年,大冰川30-40 年.

祁连山冰川前端有三道高大的终碛垅, 研究表明它是近 500 年来冷暖期交替的结果. 而 三道终碛的长度不等, 那是由于冷暖期长度不等, 寒冷期“冷储”大小不等所造成的 (图 4).

在近 500 年前的 400 年中 (1043-1426) 祁连山基本上以暖期为主，冰川“冷储”作用小， 没有形成大的终碛物,而其他终碛物为新水期第 1-3 期的产物.

致谢：施雅风教授、谢自楚、魏晋贤副教授阅读本文并提出宝贵建议,表示感谢.

\section{萦 文 献}

[1] 刘光远，喀喇尼仑山巴托拉冰川考察与研究,科学出版社，1980，99-109.

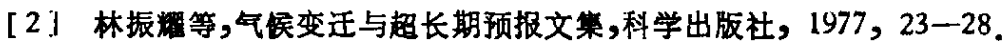

[3] 卓正大等,兰州大学学报, 1978, 2: 145-157.

[4] Fritts, H, C., Tree Ring and Climate, Academic Press, London, 1976.

[5]筸可桢,中国科学, 2(1973)，168-189.

[6] 张福春等, 气候变迁和超长期预报文集,科学出殿社, 1977, 33-35.

[7] W. M. O., Technical Note, No. 79; No, 195, 1966, T. P. 100.

[8] 王绍武等,气象学报, 37(1979), 64-73.

[.9]张家诚等,气候变迁及其原因,科学出版社，1976.

[10] 中国科学院兰州冰川冻土研究所祁连山冰䨋利用研究队,地理学报, 35(1980), 48-57. 